\title{
Smoking Related Changes in Neurotransmitters in African Americans
}

Sudhish Mishra, Anita Mandal and Prabir K. Mandal*

Department of Biology, Edward Waters College, 1658 Kings Road, Jacksonville, FL 32209, USA

\begin{abstract}
Smoking is a most common way of tobacco consumption that provides a pleasurable effect by modulating neurotransmitters in the brain. African Americans (AA) have shown higher susceptibility to nicotine consumption and highest rate of mortality due to cancer. In this study we have examined the levels of 6 neurotransmitters in AA smokers and compared them with nonsmokers of same population. We observed decrease in plasma levels of glutamate and increase in serotonin, epinephrine and dopamine. The level of gamma amino butyric acid (GABA) and norepinephrine was not changed significantly. The results, in part, explain the basis of higher nicotine susceptibility in AAs and will be helpful to develop population specific strategies for smoking cessation.
\end{abstract}

Keywords: African Americans; Neurotransmitter; Smoking; Nicotine; Tobacco

\section{Introduction}

Smoking is the most common way of tobacco consumption and it's the most difficult addiction to remove. It gives a pleasurable effect to the individuals through stimulation of dopanergic pathway [1]. However, Dopamine alone cannot be accounted for the development of addiction. Other neurotransmitters implicated in the development of addiction include serotonin, gamma amino butyric acid (GABA), glutamate and noradrenaline [2].

A range of cellular changes occurs following the repeated use of stimulants. These changes include synthesis of new proteins including transcription factors of FOS family. These transcription factors increase responsiveness to the effect of drugs [3]. These cellular changes coincide with depression, irritability and anxiety during withdrawal. Changes in neurotransmitters can also play a role in establishing the cycle of adaptation. One reason may be the down regulation of dopamine receptor. Other adaptations include changes in noradrenaline and glutanergic system [2]. These neuroadaptive changes develop responses in addicts, which force them to seek new drug supplies and begin a fresh addiction cycle.

The rate of smoking is historically higher in African Americans when compared to the general US population. Smoking related diseases kill approximately 45,000 African American each year [4]. According to epidemiological surveys smoking rate declined dramatically in African American teens since 1976 but recent trends indicate an increase of smoking among younger generation. If this trend continues, an estimated 1.6 million African Americans who are under the age of 18 will become regular smokers. About 500,000 of these smokers will die of smoking-related diseases [5]. Smoking is responsible for almost 90 percent of all lung cancer cases and also a major cause of heart disease and stroke. Heart diseases account for more deaths (27\%) in African Americans when compared to deaths due to all forms of cancer (21\%) [6].

Tobacco is obtained from Plant Nicotiana tabacum and contains an alkaloid, called Nicotine. Nicotine has been accounted as main substance responsible for forming dependence on tobacco. Nicotine is metabolized in the liver by cytochrome P450 enzymes (CYP2A6 and CYP2B6). It increases level of several neurotransmitters by binding to nicotinic acetyl choline receptors (nAChR). At high concentrations it can induce muscle contractions and respiratory paralysis [7]. Tobacco smoke contains monoamine oxidase inhibitors in addition to nicotine. Monoamine oxidase enzyme is responsible for breakdown of monoam- inergic transmitters such as dopamine, norepinephrine and serotonin. Chronic smoking also up-regulates nAChR [8]. Nicotine also activates the sympathetic nervous system, acting via splanchnic nerves to the adrenal medulla, stimulates the release of epinephrine [9].

By binding to ganglion type nicotinic receptors, Nicotine may also cause cell depolarization and influx of calcium through voltage gated calcium channels. Calcium triggers the release of epinephrine in blood stream, which causes an increase in heart rate, blood pressure and respiration [10]. Nicotine is also a vasoconstrictor, which makes harder for the heart to pump through the constricted arteries. It causes the body to release its stored fat and cholesterol into the blood. It is also speculated that nicotine also increases the risk of blood clot by increasing plasminogen activator inhibitor-1. The elevated levels of plasma fibrinogen and Factor XIII have been reported among smokers.

In the current study we have analyzed the plasma levels of 6 neurotransmitters (GABA, glutamate, serotonin, dopamine, epinephrine and norepinephrine) in African American smokers and compared the results with non-smokers of same population. Since these neurotransmitters play an important role in tobacco addiction, these results can have implications in tobacco cessation studies.

\section{Materials and Methods}

\section{Materials}

Blood samples were collected in sterile condition from 58 African American volunteers of either sex as per the institutional guidelines. Plasma were separated from collected samples by centrifugation of blood for $10 \mathrm{~min}$ and stored at $-20^{\circ} \mathrm{C}$ in aliquots until further use. ELISA kits for GABA and Glutamate were purchased from Alpco, Salem (NH). ELISA kits for Serotonin and 3-CAT (epinephrine, norepineph-

*Corresponding author: Prabir K Mandal, Department of Biology, Edward Waters College, 1658 Kings Road, Jacksonville-FL 32209, USA, Tel: 904-470-8091; Fax:904-470-8047; E-mail: prabir.mandal0807@ewc.edu

Received November 08, 2011; Accepted November 14, 2011; Published November 16, 2011

Citation: Mishra S, Mandal A, Mandal PK (2011) Smoking Related Changes in Neurotransmitters in African Americans. J Bioprocess Biotechniq 1:e106 doi: 10.4172/2155-9821.1000e106

Copyright: @ 2011 Mishra S, et al. This is an open-access article distributed unde the terms of the Creative Commons Attribution License, which permits unrestricted use, distribution, and reproduction in any medium, provided the original author and source are credited. 
Citation: Mishra S, Mandal A, Mandal PK (2011) Smoking Related Changes in Neurotransmitters in African Americans. J Bioprocess Biotechniq 1:e106 doi: 10.4172/2155-9821.1000e106

Page 2 of 4

rine and Dopamine) were purchased from Genway, San Diego (CA). Microplate reader was purchased from Bio Tek (Winooski, VT).

\section{Experimental procedure}

Plasma concentration of neurotransmitters: The plasma levels of neurotransmitters were measured by using Enzyme-linked immunosorbent assays (ELISA).

ELISAs: The ELISAs were conducted according to the manufacturers' instructions to quantify their levels in plasma of African American volunteers. Plates were read in an EPOCH ELISA reader from Biotek Instruments assay following the manufacturer's protocol and data were analyzed using GEN5 software (Biotek). For Serotonin, adrenaline, noradrenaline and dopamine, samples were acylated before ELISA. For serotonin, biotin-antiserum system was used and results were measured at $405 \mathrm{~nm}$ after conducting competitive ELISA. For adrenaline, noradrenaline and dopamine, enzyme conjugate and antiserum system was used for separate solid phase competitive ELISA and the results were measured at $450 \mathrm{~nm}$.

A
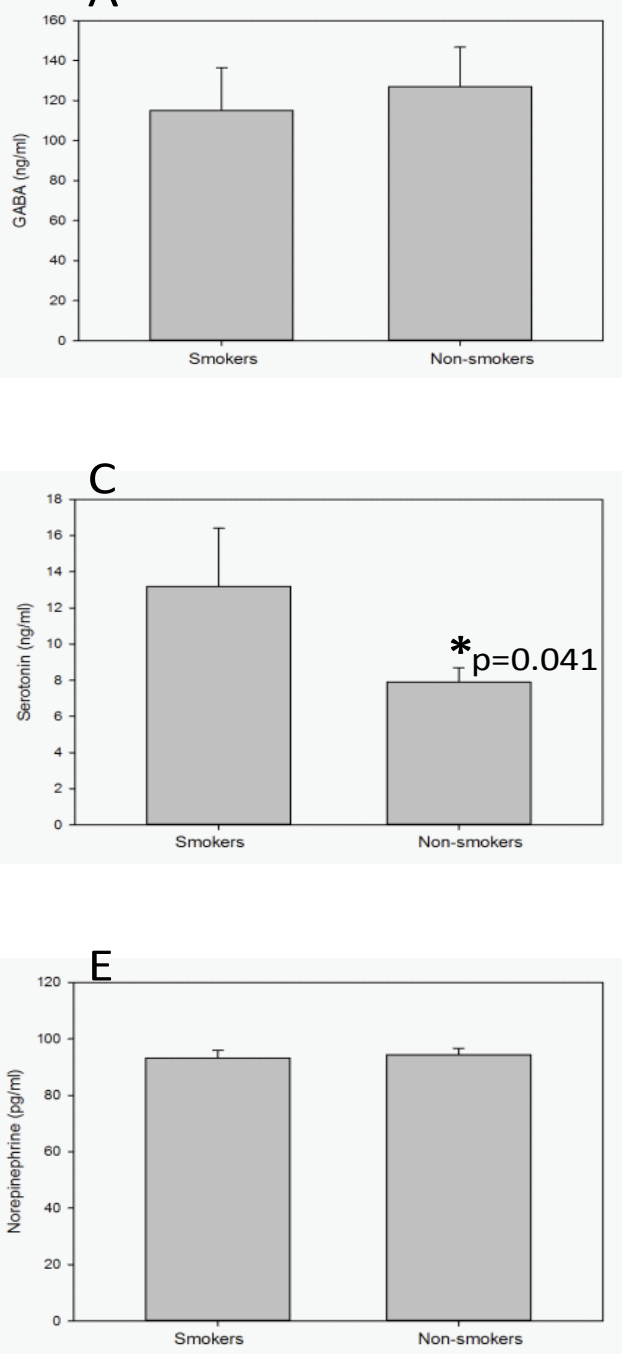

Statistical analysis: All the results were compared using Student's paired $t$-test. To determine whether significant differences in changes were present between groups, ANOVA was performed with a set to 0.05. In all instances, if significance was attained by overall ANOVA, pairwise comparisons were performed using the Student-NewmanKeuls test. For all pairwise comparisons, probability values of $\leq 0.05$ were considered significant. All data are reported as means \pm SE.

\section{Results}

\section{Regulation of GABA and glutamate}

Plasma concentration of GABA was not changed significantly when volunteer smokers were compared with non-smoker volunteers (115.1 \pm 21.3 vs. $126.9 \pm 19.9 ; \mathrm{ng} / \mathrm{ml}$; Figure1A).

Plasma concentration of Glutamate was found significantly decreased $(12.1 \pm 2.5$ vs. $19.7 \pm 2.5 ; \mu \mathrm{g} / \mathrm{ml})$ in smokers when compared to non-smokers (Figure1B).

\section{B}
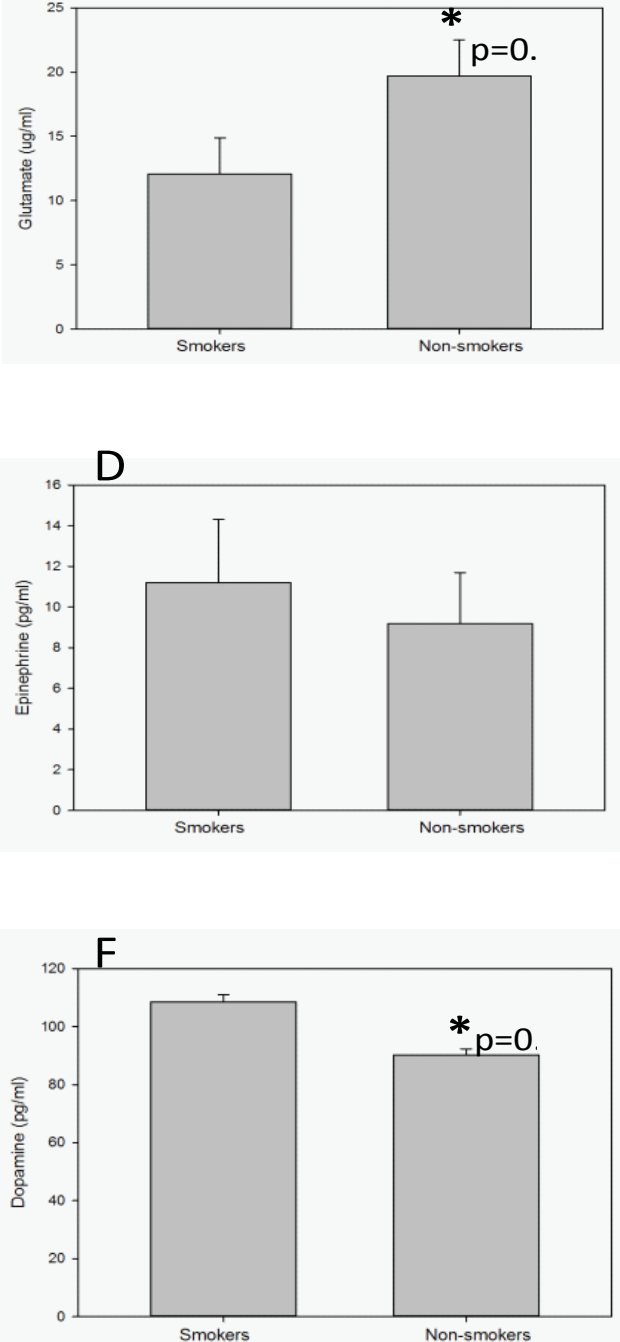

Figure1: Plasma concentrations of neurotransmitters in smoker and non-smoker African American volunteers. A: GABA; B: Glutamate; C:Serotonin; D: Epinephrine; E: Norepinephrine; F: Dopamine; ${ }^{*} \mathrm{p}<0.05$ vs smokers. 


\section{Up-regulation of serotonin}

Plasma concentration of serotonin significantly increased (13.2 \pm 2.8 vs. $7.9 \pm 0.8 ; \mathrm{ng} / \mathrm{ml}$ ) in smokers when compared to non-smokers (Figure1C).

\section{Regulation of epinephrine, norepinephrine and dopamine}

Plasma concentration of epinephrine was slightly increased $(11.2 \pm 3.1$ vs. $9.2 \pm 2.5$; pg/ml; Figure1D) in smoker volunteers when compared to non-smokers but concentration of norepinephrine was not changed significantly ( $93.1 \pm 2.7$ vs. $94.3 \pm 2.4 ; \mathrm{pg} / \mathrm{ml}$; Figure $1 \mathrm{E})$. The concentration of Dopamine was found significantly increased in smokers $(108.5 \pm 2.6$ vs. $90.2 \pm 2.1 ; \mathrm{pg} / \mathrm{ml})$ when compared to non-smokers (Figure1F).

\section{Discussion}

In the present study we have identified the alteration in neurotransmitter levels in smokers of African American population. During this study we measured the plasma levels of GABA, Glutamate, serotonin, epinephrine, norepinephrine and dopamine. The results were analyzed by comparing with non-smokers.

Gamma-aminobutyric acid (GABA) is a multifunctional mediator that functions as a neurotransmitter in the central nervous system and $[11,12]$ is responsible for controlling dopamine release through receptors present on dopamine releasing neurons. Because of its role in nicotine addiction pathway, GABA has been considered a very useful target for nicotine addiction therapies [13]. Nicotine and/or cigarette smoking modulates brain gamma aminobutyric acid (GABA) concentrations in animals and humans [14,15]. Our results show slight decrease in GABA concentration among smokers but it was not found statistically significant. These findings of reduced GABA are in accord with investigations for tobacco specific carcinogen that have revealed a reduction of GABA in the lungs and small airway-derived pulmonary adenocarcinoma of smokers [16].

Glutamate is an amino acid neurotransmitter responsible for creating and storing memories in the brain. Each time a nicotine dependent individual smokes or chews a memory of alertness (from the acetylcholine) and pleasure (from the dopamine) reinforces the desire for continued nicotine consumption. Glutamate also synthesizes GABA through the action of glutamic acid carboxylase [17]. We have observed significant reduction in glutamate levels among smokers [18]. These results are in contrast to the results reported for hippocampus and cingulate cortex region of brain, where no change in glutamate concentration was found among smokers [19].

Serotonin is the "feel good" neurotransmitter of the brain and is responsible for us feeling happy, relaxed, calm, motivated, and at peace with our lives and our role in the world. Low level of serotonin is associated with stress, food craving, obesity, poor memory, fatigue, insulin resistance, insomnia, food intolerance, heart disease and smoking addiction [20].

Smoking causes decrease in the serotonin receptors in the brain which stop it being flooded with the body's natural stress-busting hormone, serotonin. It makes smokers feel deficient in serotonin and therefore they are less able to cope with the everyday pressures of life and suffer from high levels of stress [21]. Smokers enjoy short term relief from their anxiety because nicotine temporarily increases levels of dopamine. We observed significant increase in plasma serotonin level in smokers [22]. These results are in agreement with earlier reports where investigators observed higher levels of platelet [23] and plasma serotonin [24] in smokers.

Epinephrine and norepinephrine are catecholamine, secreted by adrenal gland and is responsible for fight or flight response of sympathetic nervous system. These neurotransmitters exert their tissue specific effect by binding to their specific receptors expressed in target tissue [25].In our study, we observed slight increase in plasma epinephrine level in African American smokers but norepinephrine levels were not changed. These results are in agreement with earlier studies to measure nicotine effect on these catecholamines in plasma [26-28] and serum [29], where they found increased level of epinephrine but not of norepinephrine. Some other studies have shown increased plasma level of both catecholamines after smoking [30,31].

Dopamine, another catecholamine neurotransmitter of brain and precursor of norepinephrine and epinephrine has widely implicated for smoking addiction. Smoking increases the level of dopamine in the body, which stimulates reward centers in the brain. This process reinforces the smoking behavior, so that each cigarette makes smokers desire yet another [32].Our results of increased dopamine level in plasma of smokers are in agreement of earlier studies for its concentration in basal ganglia of brain in smokers $[33,34]$.

African Americans show higher susceptibility to various types of cancer and cardiac abnormalities. Smoking behavior further increases the chances of disease manifestation. Present population specific study of neurotransmitters has provided some information to understand the pathophysiology of AA smokers and will be helpful to control smoking behavior.

\section{Grant}

This study was supported by James \& Esther King Biomedical Research Program of Florida Department of Health Grant HBC-01 to Drs. Prabir K. Mandal (PI), Sudhish Mishra (Co-PI) and Anita Mandal (CoPI) of Biology Department, EWC.

\section{References}

1. Koob GF, Le Moal M (1997) Drug abuse: Hedonic homeostatic dysregulation Science 278: 52-58.

2. Delfs JM, Zhu Y, Druhan JP, Aston-Jones G (2000) Noradrenaline in the ventra forebrain is critical for opiate withdrawal-induced aversion. Nature 403: 430434

3. Kelz MB, Chen J, Carlezon WA Jr, Whisler K, Gilden L, et al. (1999) Expression of the transcription factor deltaFosB in the brain controls sensitivity to cocaine. Nature 401: 272-276.

4. CDC (1995) Office on Smoking and Health, Unpublished Data.

5. CDC (1998) At A Glance. Tobacco use among US racial/Ethnic Minority Groups-African Americans, American Indians and Alaska Natives and Hispanics, Atlanta.

6. American Cancer Society (2005-2006)Cancer Facts and Figures for African Americans.

7. Katzung BG (2006) Basic and Clinical Pharmacology. New York: McGraw-Hil Medical Pp. 99-105.

8. Walsh H, Govind AP, Mastro R, Hoda JC, Bertrand D, et al. (2008) Up-regulation of nicotinic receptors by nicotine varies with receptor subtype. J Biol Chem 283: 6022-6032.

9. Yoshida T, Sakane N, Umekawa T, Kondo M (1994) Effect of nicotine on sympathetic nervous system activity of mice subjected to immobilization stress Physiol Behav 55: 53-57.

10. Marieb EN, Hoehn K (2007) Human Anatomy \& Physiology (7th Ed.). Pearson Benzamin Cummings. 
Citation: Mishra S, Mandal A, Mandal PK (2011) Smoking Related Changes in Neurotransmitters in African Americans. J Bioprocess Biotechniq 1:e106 doi: 10.4172/2155-9821.1000e106

11. Owens DF, Kriegstein AR (2002) Is there more to GABA than synaptic inhibition? Nat Rev Neurosci 3: 715-727.

12. Watanabe M, Maemura K, Kanbara K, Tamayama T, Hayasaki H (2002) GABA and GABA receptors in the central nervous system and other organs. Int Rev Cytol 213: 1-47.

13. Mason G (2007) Nicotine has significant effects on brain GABA. American College of Neuropsychopharmacology (ACNP) Annual meeting

14. Epperson C N, O'Malley S, Czarkowski K A, Gueorguieva R, Jatlow P, et al (2005) Sex, GABA, and nicotine: the impact of smoking on cortical GABA levels across the menstrual cycle as measured with proton magnetic resonance spectroscopy. Biological Psychiatry 57: 44-48.

15. Zhu PJ, Chiappinelli VA (1999) Nicotine modulates evoked GABAergic transmission in the brain. Journal of Neurophysiology 82: 3041-3045.

16. Schuller HM, Al-Wadei HA, Majidi M (2008) Gamma-aminobutyric acid, a potential tumor suppressor for small airway-derived lung adenocarcinoma Carcinogenesis 29: 1979-1985.

17. How Nicotine Addiction Really Works.

18. Wang G, Wang R, Ferris B, Salit J, Strulovici-Barel Y, et al. (2010) Smokingmediated up-regulation of GAD67 expression in the human airway epithelium Respiratory Research 11: 150-164.

19. Gallinat J, Schubert F (2007) Regional cerebral glutamate concentrations and chronic tobacco consumption. Pharmacopsychiatry 40: 64-67.

20. Berger M, Gray JA, Roth BL (2009) The expanded biology of serotonin. Annu Rev Med 60: 355-366.

21. Xu Z, Seidler FJ, Cousins MM, Slikker W Jr, Slotkin TA (2002) Adolescent nicotine administration alters serotonin receptors and cell signaling mediated through adenylyl cyclase. Brain Res 951: 280-292.

22. Stokes C, Watson J (2004) Smokers Have Serotonin Deficiency Causing High Stress Levels. Scotsman.com

23. Racké K, Schwörer H, Simson G (1992) Effects of cigarette smoking or ingestion of nicotine on platelet 5-hydroxytryptamine (5-HT) levels in smokers and non-smokers. Clin Investig 70: 201-204.
24. Sugiura T, Dohi Y, Yamashita S, Hirowatari Y, Yatomi Y, et al. (2010) Increase of plasma serotonin mediates impaired endothelial function in habitual smokers. Eur Heart J 31: Abstract Supplement: 682.

25. Berecek Kh, BM (1982) Evidence for a neurotransmitter role for epinephrine derived from the adrenal medulla. Am J Physiol 242: H593-H601.

26. Trap-Jensen J, Carlsen JE, Svendsen TL, Christensen NJ (1979) Cardiovascular and adrenergic effects of cigarette smoking during immediate non-selective and selective beta adrenoceptor blockade in humans. European Journal of Clin Invest 9: 181-183.

27. Myers MG, Benowitz NL, Dubbin JD, Haynes RB, Sole MJ (1988) Cardiovascular Effects of Smoking in Patients with Ischemic Heart Disease. Chest 93 14-19.

28. Wolk R, Shamsuzzaman ASM, Svatikova A, Huyber CM, Huck C, et al. (2005) Hemodynamic and autonomic effects of smokeless tobacco in healthy young men. J Am Coll Cardiol 45: 910-914.

29. Hill P, Wynder EL (1974) Smoking and cardiovascular disease. Effect of nicotine on the serum epinephrine and corticoids. Am Heart J 87: 491-496.

30. Walker JF, Collins LC, Rowell PP, Goldsmith LJ, Stamford BA, et al. (1999) The effect of smoking on energy expenditure and plasma catecholamine and nicotine levels during light physical activity. Nicotine Tob Res 1: 365-370.

31. Siess W, Lorenz R, Roth P, Weber PC (1982) Plasma Catecholamines, Platele Aggregation and Associated Thromboxane Formation After Physical Exercise, Smoking or Norepinephrine Infusion. Circulation 66: 44-48.

32. Arias-Carrión O, Pöppel E (2007) Dopamine, learning and reward-seeking behavior. Act Neurobiol Exp 67: 481-488.

33. Court JA, Lloyd S, Thomas N, Piggott MA, Marshall EF, et al. (1998) Dopamine and nicotinic receptor binding and the levels of dopamine and homovanillic acid in human brain related to tobacco use. Neuroscience $87: 63-78$.

34. Salokangas RKR, Vilkman H, llonen T, Taiminen T, Bergman J, et al. (2000) High Levels of Dopamine Activity in the Basal Ganglia of Cigarette Smokers. Am J Psychiatry 157: 632-634. 